\section{Two-hole extracapsular technique for the repair of canine cranial cruciate ligament rupture in thirty-eight dogs}

\author{
Mitsuhiro Isaka, Masahiko Befu, \\ Nami Matsubara, Mayuko Ishikawa, \\ Yurie Arase, Akiko Doi, Shinichi Namba \\ Marble Veterinary Medical Center, \\ Fujisawa, Japan
}

\section{Abstract}

Extracapsular technique with lateral fabellar suture (LFS) is one of the commonest surgical techniques for canine cranial cruciate ligament (CRCL) rupture. Among LFS methods, parallel double holes in the tibia are the most effective for the repair of canine stifle joint. The aim of this study was to evaluate the effectiveness of two-hole LFS for canine CRCL rupture. We retrospectively evaluated the outcome of canine CRCL rupture treated with two-hole LFS technique performed by two surgeons from October 2011 to September 2013.

Breeds included Beagle ( $n=5)$, Yorkshire terrier $(\mathrm{n}=5)$, German shepherd $(\mathrm{n}=4)$, and so on. Mean body weight was $14.0 \pm 11.6 \mathrm{~kg}$ ( $>10$ kg: $n=16,<10 \mathrm{~kg}: \mathrm{n}=22)$. Body condition score (5 scales) was as follows: $1(\mathrm{n}=0), 2(\mathrm{n}=1), 3$ $(\mathrm{n}=18), 4(\mathrm{n}=18)$, and $5(\mathrm{n}=1)$. There were 18 males [neutered $(n=11)$ ] and 20 females [spayed $(n=12)$ ]. Mean age was $83.4 \pm 44.8$ months (>12 months: $\mathrm{n}=35,<12$ months: $n=3)$. The type of rupture was partial $(n=17)$ and complete $(\mathrm{n}=21)$. The affected site was right $(\mathrm{n}=20)$, left $(\mathrm{n}=18)$, and bilateral $(\mathrm{n}=4)$. Rehabilitation after operation was needed in 8 cases. There were 12 cases of previous medial patellar luxation operation, and 6 cases of opposite site CRCL surgery. Start of weight bearing and resolution of extension function was on day $1(\mathrm{n}=30)$, day $2(\mathrm{n}=0)$, and after day $2(n=8)$. There was no evidence of surgical site infection/inflammation in any cases. The results of this study showed that two-hole LFS is an easy and effective technique for the repair of canine CRCL.

\section{Introduction}

Canine cranial (or anterior) cruciate ligament (CRCL) rupture is one of the most common orthopedic conditions. Unlike in people, where trauma is the most common etiology of the disease, CRCL rupture is multifactorial in origin. Regardless of cause, CRCL rupture results in stifle instability, which sets into motion a cascade of events including synovitis, articular cartilage degeneration, periarticular osteophyte development, capsular fibrosis, and medial meniscus injury. Progressive osteoarthritis is the end result after CRCL rupture regardless of treatment; however, the severity of osteoarthritis may be attenuated with early surgical intervention. ${ }^{1}$

Surgical treatment of CRCL injury may be divided into two categories: extracapsular (outside of the joint) and intracapsular (inside the joint) techniques. The surgical treatment chosen is largely a matter of the surgeon's preference, as several retrospective studies have shown that the success rate of any technique is near $90 \% .2,3$

Intracapsular techniques attempt to stabilize the knee by replacing the ruptured CRCL by passing an autologous tissue or synthetic graft through the joint. There are varieties of intracapsular techniques available, which differ only in the placement of the graft. Most surgeons performing an intracapsular technique will often augment the repair with an extracapsular reconstruction. Some of the most common intracapsular techniques are over-the-top procedure, under-and-over technique, Paatasama technique, and arthroscopic placement of the graft. ${ }^{4}$

In contrast, extracapsular techniques usually involve the placement of sutures outside the joint or redirection of the lateral collateral ligament. Two other procedures, called the tibial plateau leveling osteotomy (TPLO) and the tibial tuberosity advancement (TTA), alter the biomechanics of the joint so that the animal can bear weight and walk without a cranial cruciate ligament. These procedures, in particular, have a steep learning curve and should only be performed by a veterinary surgeon with advanced training. Some of the most common extracapsular techniques are lateral fabellar suture (LFS) or retinacular stabilization, imbrication technique, fibular head transposition, TPLO, TTA and TightRope ${ }^{\circledR}$ (Arthrex Vet Systems, Naples, Florida, USA). Regardless of the technique used to stabilize the stifle, the meniscus should be inspected for tears or other evidence of trauma or prophylactically released to prevent entrapment. Damage to the caudal body of the medial meniscus is seen in $50 \%$ to $75 \%$ of patients with a ruptured CRCL. ${ }^{1-6}$ When comparing between LFS and TTA/TPLO, dogs achieve normal limb loading faster after TPLO than LFS. TPLO results in operated limb function that is indistinguishable from that of the control population 1 year postoperatively. ${ }^{7}$ However, LFS technique has significantly lower rate of infection/inflammation, than TPLO (4.2\% vs 8.4\%). ${ }^{8}$ Thus, in part, TTA/TPLO might be not the best surgical technique for the repair of CRCL rupture.

Two-hole extracapsular technique might be
Correspondence: Mitsuhiro Isaka, Marble Veterinary Medical Center, 4-1-6 Ishikawa, Fujisawa, Kanagawa 252-0815, Japan.

Tel.: +81.466.862.080 - Fax: +81.466 .860 .558 .

E-mail: isakam7@gmail.com

Key words: veterinary, animals, surgery.

Contributions: the authors contributed equally.

Received for publication: 6 January 2014. Accepted for publication: 4 February 2014.

This work is licensed under a Creative Commons Attribution NonCommercial 3.0 License (CC BYNC 3.0).

(C) Copyright M. Isaka et al., 2014

Licensee PAGEPress srl, Italy

Veterinary Science Development 2014; 4:5284

doi:10.4081/vsd.2014.5284

the preferred method when attempting to stabilize the stifle with a lateral suture, as this method has consistently resulted in the least change in suture tension in canine stifle joints, compared to other suture attachments points such as the Flo method. Tightening should be performed with the stifle in slight extension rather than in flexion. ${ }^{9}$ However, there has been no report about the surgical results of two-hole LFS techniques for canine CRCL rupture. Further, in general, risk factors for CRCL rupture include large, active dogs, obesity, and animals that participate in the weekend warrior syndrome (intermittent excessive activity by inactive dogs and their owners). However, most of owned dogs are small breeds in Japan.

The purpose of this study was to evaluate the effectiveness of two-hole LFS technique for the repair of canine CRCL rupture.

\section{Materials and Methods}

We retrospectively evaluated canine CRCL rupture treated with two-hole LFS technique from October 2011 to September 2013 (Figure 1) using nylon reader line. Operations were performed by two surgeons (Isaka and Befu).

As shown in Table 1, breeds were Beagle $(\mathrm{n}=5)$, Yorkshire Terrier $(\mathrm{n}=5)$, German shepherd $(n=4)$, Toy poodle $(n=3)$, Papillon $(n=3)$, Labrador retriever $(n=2)$, Bernese mountain $\operatorname{dog}(n=2)$, Miniature Schnauzer $(n=2)$, Shiba $(n=2)$, Bulldog $(n=2)$, Pomeranian $(n=2)$, Mixed $(n=2)$, Maltese $(n=1)$, Pembroke Welsh Corgi $(n=1)$ and West Highland White Terrier $(n=1)$. Perioperative antimicrobial use has certain discrepancies (there is no standard guideline for usage of antibiotics) in veteri- 
nary practice for the operation of canine CRCL rupture. ${ }^{10}$ For this reason, we administered antibiotics pre-operatively (subcutaneously), 3 days postoperatively treatment (intravenously), and 7 days postoperatively (oral) after removing the suture.

\section{Results}

As shown in Table 2, mean body weight was $14.0 \pm 11.6 \mathrm{~kg}$ (>10 kg: $n=16,<10 \mathrm{~kg}: \mathrm{n}=22)$. Body condition score (5 scales) was as follows: $1(\mathrm{n}=0), 2(\mathrm{n}=1), 3(\mathrm{n}=18), 4(\mathrm{n}=18)$, and 5 $(n=1)$. There were 19 males (neutered $n=11$ ) and 20 females (spayed $n=12$ ). Mean age was $83.4 \pm 44.8$ months ( $>12$ months: $n=35,<12$ months: $n=3$ ). The type of rupture was partial $(n=17)$ and complete $(n=21)$. The affected site was right $(\mathrm{n}=20)$, left $(\mathrm{n}=18)$, and bilateral $(n=4)$. Rehabilitation after operation was needed in 8 cases. Both were 12 cases of previous medial patellar luxation (MPL) operation, and 6 cases of opposite site CRCL surgery. Start of weight bearing and resolution of extension function was on day $1(\mathrm{n}=30)$, day 2 $(\mathrm{n}=0)$, and after day $2(\mathrm{n}=8)$. Operation time was $71.8 \pm 6.2 \mathrm{~min}$ for bilateral cases and $46.5 \pm 10.3 \mathrm{~min}$ for unilateral cases. There was no surgical site infection/inflammation in any cases.

\section{Discussion and Conclusions}

In our retrospective study, two-hole LFS technique showed good surgical results. An ex vivo study showed that double holes at the tibial crest had the least change in suture tension across the range of motion in canine stifle joint, compared to other lateral suture attachments points (e.g., Flo method and so on). ${ }^{9}$ However, there was no report about the efficacy of this method in clinical cases. Our study showed that this method might be excellent among LFS methods.

Inter- and intra- operator variability associated with extracapsular suture tensioning during lateral fabello-tibial suture placement was determined in the above-mentioned ex vivo study. The mean difference within the three operators ranged from 0 to $14.7 \mathrm{~N}$. With $95 \%$ limits of agreement, on most occasions for all three operators, the difference was between -31.7 and $41.0 \mathrm{~N}$. The mean difference between the three operators ranged from 6.0 to $30.7 \mathrm{~N}$. With $95 \%$ limits of agreement, on most occasions, the difference between operators was between -25.6 and $62.5 \mathrm{~N}$. Marked variation exists in the tension applied during fabello-tibial suture application, both within and between surgeons. This variation may lead to inconsistent clinical outcomes. Further studies are required to determine the clinical consequences of this marked variation in extracapsular suture tensioning. 5

To determine whether an extracapsular patellar ligament/fascia lata graft would provide stability to the CRCL-deficient stifle that is comparable with that of the intact stifle, and to determine if different tibial anchor points would enhance stability of the CRCL-deficient stifle when compared with standard LFS placement, stifles from 28 canine cadaver hind

Table 1. Characteristics.

\begin{tabular}{ll}
\hline Breed & No. \\
Maltese & 1 \\
Beagle & 5 \\
\hline MIX & 2 \\
Labrador retriever & 2 \\
\hline Bernese mountain dog & 2 \\
Miniature Schnauzer & 2 \\
\hline T. Poodle & 3 \\
Shiba & 2 \\
\hline Pembroke Welsh Corgi. & 1 \\
Yorkshire Terrier & 5 \\
\hline Bulldog & 2 \\
Pomeranian & 2 \\
\hline Papillon & 3 \\
German shepherd & 4 \\
\hline West Highland White Terrier & 1 \\
\hline
\end{tabular}

Table 2. Summary.

\begin{tabular}{|c|c|}
\hline Characteristics & No. \\
\hline $\begin{array}{l}\text { Body weight } \\
\quad>10 \mathrm{~kg} \\
<10 \mathrm{~kg}\end{array}$ & $\begin{array}{c}14.0 \pm 11.6(\mathrm{~kg}) \\
n=16 \\
n=22\end{array}$ \\
\hline $\begin{array}{c}\text { Body condition score } \\
1 \\
2 \\
3 \\
4 \\
5\end{array}$ & $\begin{array}{l}n=0 \\
n=1 \\
n=18 \\
n=18 \\
n=1\end{array}$ \\
\hline $\begin{array}{l}\text { Male } \\
\text { Neutered }\end{array}$ & $\begin{array}{l}n=18 \\
n=11\end{array}$ \\
\hline $\begin{array}{l}\text { Female } \\
\text { Spayed }\end{array}$ & $\begin{array}{l}n=20 \\
n=12\end{array}$ \\
\hline $\begin{array}{l}\text { Age mean } \\
\quad>12 \text { months } \\
\quad<12 \text { months }\end{array}$ & $\begin{array}{c}83.4 \pm 44.8 \text { moinths } \\
n=35 \\
n=3\end{array}$ \\
\hline $\begin{array}{l}\text { Partial or complete } \\
\text { Partial } \\
\text { Complete }\end{array}$ & $\begin{array}{l}\mathrm{n}=17 \\
\mathrm{n}=21\end{array}$ \\
\hline $\begin{array}{l}\text { Lateral } \\
\text { Right } \\
\text { Left } \\
\text { Bilateral }\end{array}$ & $\begin{array}{l}n=20 \\
n=18 \\
n=4\end{array}$ \\
\hline Rehabilitation & $n=8$ \\
\hline $\begin{array}{l}\text { Prevalence number of } \\
\text { previous MPL operation }\end{array}$ & $n=12$ \\
\hline $\begin{array}{l}\text { Prevalence number of } \\
\text { opposite site ACL }\end{array}$ & $\mathrm{n}=6$ \\
\hline $\begin{array}{l}\text { Start of bearing/disappea } \\
\text { Day } 1 \\
\text { Day } 2 \\
\text { After day } 2\end{array}$ & $\begin{array}{l}n \operatorname{ling} \\
\mathrm{n}=30 \\
\mathrm{n}=0 \\
\mathrm{n}=8\end{array}$ \\
\hline $\begin{array}{l}\text { Operation time } \\
\text { Bilateral } \\
\text { Lateral }\end{array}$ & $\begin{array}{l}71.8 \pm 6.2(\mathrm{~min}) \\
46.5 \pm 10.3(\mathrm{~min})\end{array}$ \\
\hline urgical site infection- & $\mathrm{n}=0$ \\
\hline
\end{tabular}

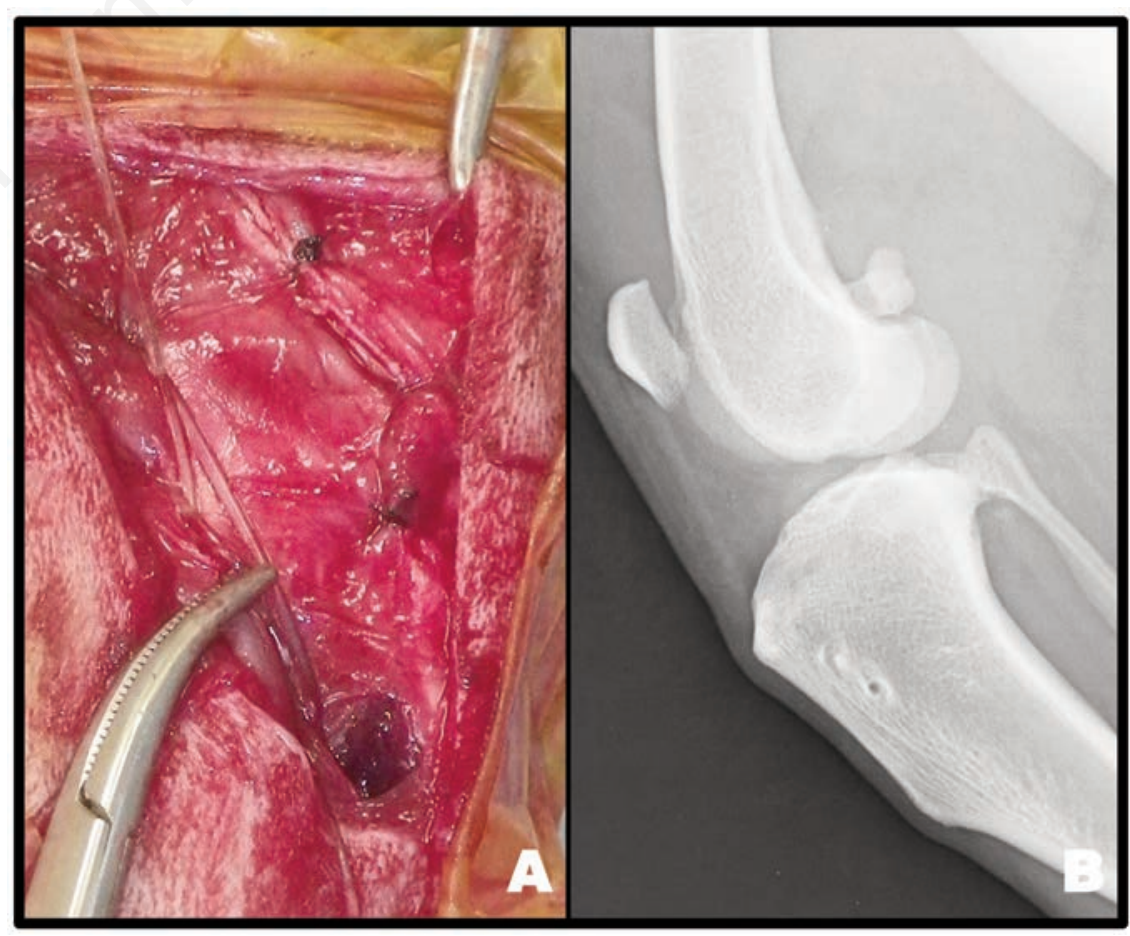

Figure 1. Canine cranial cruciate ligament rupture. 
limbs were mounted in a jig and tested between loads of -65 and $80 \mathrm{~N}$. After testing the intact CRCL, 4 stabilization techniques were tested after CRCL transection: lateral graft technique (LGT) and 3 FTS techniques with different tibial anchor points. There were no significant differences in displacement between the LGT and standard LFS, between the LGT and the intact CRCL, or between the LFS and the intact CRCL, in either the Securos or the Screw-washer experiments. Stiffness of the intact CRCL was significantly greater than that of any stabilization technique and the cut CRCL. The standard LFS showed the least displacement of all suture stabilization techniques. Differences in stiffness were not significant between the suture stabilization techniques. Securely anchored, the LGT results in a reduction in drawer motion similar to that of the intact CRCL and the standard LFS. Altering the tibial anchor point for the LFS does not improve stiffness or enhance stabilization of the CRCL-deficient stifle. The LGT could be used for the treatment of CRCL ruptures in the dog. A clinical study is recommended. 11

In one study about 266 canine stifle joints (104 cases), the association between severity of MPL and CCLR had good correlations. Thus, $41 \%$ out of 104 MPL cases had concomitant CCLR. ${ }^{12}$ In our study, the number of dogs with previous MPL operation was similar $(\mathrm{n}=12$, $31.6 \%$ ). There might be an association between MPL and ACL regardless of a previous condition. However, a definite association is still to be established.

The lateral extracapsular suture system (LESS) procedure effectively decreased cranial tibial displacement and eliminated internal rotation of the tibia relative to the femur in the CRCL-deficient stifles at stifle angles of $125^{\circ}$, $135^{\circ}$, and $145^{\circ}$ in vitro. 6 To mimic that, we performed clotting on $135^{\circ}$ during the operation.

As for the type pf suture, an in vitro study showed that, Nylon Leader Line construct is mechanically superior to Orthofiber ${ }^{\circledR}$ (Contour Living, Charlotte, NC, USA) construct. 13 This is why we used a nylon leader in our study. To describe a method of tightening nylon loops secured with a crimping system for extracapsular fabello-tibial stabilization of the cranial cruciate ligament-deficient stifle and to compare this with a method using a commercially available tensioning device, in vitro mechanical testing was performed. The hand tightening method does not affect the mechanical properties of the loop. The hand tightening method described is a valuable technique for unassisted surgeons without access to tensioning devices. 14 More recently, modified LFS for canine CCLR showed good surgical results in large breed dogs. 15 The same was observed with a modified LFS technique, which resulted in 6-month outcomes that were not different from those of TPLO in terms of radiographic progression of $\mathrm{OA}$ and client-evaluated level of function. ${ }^{16}$ In general, complications of CCLR injury include osteoarthritis (degenerative joint disease), meniscal tears, loss of joint range of motion in the stifle, muscle atrophy of the affected limb, loss of athletic ability and full function of the affected limb, and rupture of the opposite cranial cruciate ligament. However, there is only one retrospective study that described the complications associated with CCLR injury. In 808 dogs (902 procedures) with extracapsular lateral suture stabilization or tibial plateau leveling osteotomy, Frey et al. retrospectively evaluated post-operative infection/inflammation. Infection/inflammation developed in 55 of 902 (6.1\%) surgeries within 6 months after surgery. There was a significant difference in infection/inflammation rate after LFS surgery [21/496 (4.2\%)], compared with the rate after TPLO [34/406 (8.4\%)]. 8 Thus, in this part, LFS might be better surgical technique than TPLO. However, we did not evaluate this method for long term outcome focused on osteoarthritis. Although rehabilitation during the postoperative period for canine CCLR well established, in our study, we did not perform the rehabilitation for all cases. ${ }^{17,18}$ Only $21.1 \%(8 / 38)$ needs rehabilitation. Our rehabilitation protocol did not include electric muscular stimulation, because it might increase meniscal damage in dogs. ${ }^{19}$ Instead, we performed aquatic rehabilitation because it would likely result in better overall outcome than walking alone. ${ }^{20}$ All cases showed acute onset, and surgical timing within 2 weeks was observed in 36 cases, compared to that after 2 weeks in only 2 cases in our study. Surgical timing for CRCL rupture is controversial in human medicine. One report showed there was no difference in clinical outcome between CRCL patients who underwent early rather compared to delayed CRCL reconstruction. ${ }^{21}$ To the contrary, there was a significantly higher incidence of meniscal tears in patients undergoing reconstruction in delayed surgical timing. ${ }^{22}$ Collectively, there was no significant difference in surgical result between early and delay surgical timing in veterinary medicine. However, it is possible that early surgical timing is better.

In conclusion, two-hole LFS technique for the reconstruction of canine CRCL rupture is an easy and safe technique with good surgical result. Evaluation of long-term surgical outcomes on osteoarthritis and direct comparison with other surgical techniques are needed.

\section{References}

1. Hayashi K, Manley PA, Muir P. Cranial cruciate ligament pathophysiology in dogs with cruciate disease: a review. J Am Anim
Hosp Assoc 2004:40:385-90.

2. Christopher SA, Beetem J, Cook JL. Comparison of long-term outcomes associated with three surgical techniques for treatment of cranial cruciate ligament disease in dogs. Vet Surg 2013;42:329-34.

3. Moore KW, Read RA. Cranial cruciate ligament rupture in the dog--a retrospective study comparing surgical techniques. Aust Vet J 1995;72:281-5.

4. Jerram RM, Walker AM. Cranial cruciate ligament injury in the dog: pathophysiology, diagnosis and treatment. $\mathrm{N}$ Z Vet $\mathrm{J}$ 2003; 51:149-58.

5. Dunn AL, Buffa EA, Marchevsky AM, et al. Inter- and intra-operator variability associated with extracapsular suture tensioning: an ex vivo study. Vet Comp Orthop Traumatol 2012;25:472-7.

6. D'Amico LL, Lanz OI, Aulakh KS, Butler JR, et al. The effects of a novel lateral extracapsular suture system on the kinematics of the cranial cruciate deficient canine stifle. Vet Comp Orthop Traumatol 2013;26: 271-9.

7. Nelson SA, Krotscheck U, Rawlinson J, et al. Long-term functional outcome of tibial plateau leveling osteotomy versus extracapsular repair in a heterogeneous population of dogs. Vet Surg 2013;42:38-50.

8. Frey TN, Hoelzler MG, Scavelli TD, et al. Risk factors for surgical site infectioninflammation in dogs undergoing surgery for rupture of the cranial cruciate ligament: 902 cases (2005-2006). J Am Vet Med Assoc 2010;236:88-94.

9. Fischer C, Cherres M, Grevel V, et al. Effects of attachment sites and joint angle at the time of lateral suture fixation on tension in the suture for stabilization of the cranial cruciate ligament deficient stifle in dogs. Vet Surg 2010;39:334-42.

10. Weese JS, Halling KB. Perioperative administration of antimicrobials associated with elective surgery for cranial cruciate ligament rupture in dogs: 83 cases (2003-2005). J Am Vet Med Assoc 2006;229:92-5.

11. Harper TA, Martin RA, Ward DL, Grant JW. An in vitro study to determine the effectiveness of a patellar ligament/fascia lata graft and new tibial suture anchor points for extracapsular stabilization of the cranial cruciate ligament-deficient stifle in the dog. Vet Surg 2004;33:531-41.

12. Campbell CA, Horstman CL, Mason DR, Evans RB. Severity of patellar luxation and frequency of concomitant cranial cruciate ligament rupture in dogs: 162 cases (20042007). J Am Vet Med Assoc 2010;236:88791.

13. Cabano NR, Troyer KL, Palmer RH, et al. Mechanical comparison of two suture constructs for extra-capsular stifle stabiliza- 
tion. Vet Surg 2011;40:334-9.

14. Moores AP, Beck AL, Jespers KJ, Wilson AM. Mechanical evaluation of two loop tensioning methods for crimp clamp extracapsular stabilization of the cranial cruciate ligament-deficient canine stifle. Vet Surg 2006;35:476-9.

15. Guénégo L, Zahra A, Madelénat A, et al. Cranial cruciate ligament rupture in large and giant dogs. A retrospective evaluation of a modified lateral extracapsular stabilization. Vet Comp Orthop Traumatol 2007;20:43-50.

16. Cook JL, Luther JK, Beetem J, Karnes J, Cook CR. Clinical comparison of a novel extracapsular stabilization procedure and tibial plateau leveling osteotomy for treat- ment of cranial cruciate ligament deficiency in dogs.Vet Surg. 2010; 39: 315-23.

17. Marsolais GS, Dvorak G, Conzemius MG. Effects of postoperative rehabilitation on limb function after cranial cruciate ligament repair in dogs. $\mathrm{J}$ Am Vet Med Assoc. 2002;220: 1325-30.

18. Jerre S. Rehabilitation after extra-articular stabilisation of cranial cruciate ligament rupture in dogs. Vet Comp Orthop Traumatol. 2009; 22: 148-52.

19. Johnson JM, Johnson AL, Pijanowski GJ, et al. Rehabilitation of dogs with surgically treated cranial cruciate ligament-deficient stifles by use of electrical stimulation of muscles. Am J Vet Res 1997;58:1473-8.

20. Marsolais GS, McLean S, Derrick T,
Conzemius MG. Kinematic analysis of the hind limb during swimming and walking in healthy dogs and dogs with surgically corrected cranial cruciate ligament rupture. J Am Vet Med Assoc 2003;222:739-43.

21. Smith TO, Davies L, Hing CB. Early versus delayed surgery for anterior cruciate ligament reconstruction: a systematic review and meta-analysis. Knee Surg Sports Traumatol Arthrosc 2010;18:304-11.

22. Church S, Keating JF. Reconstruction of the anterior cruciate ligament: timing of surgery and the incidence of meniscal tears and degenerative change. J Bone Joint Surg Br 2005;87:1639-42. 